\title{
Diversity focused semisyntheses of tetronate polyether ionophores
}

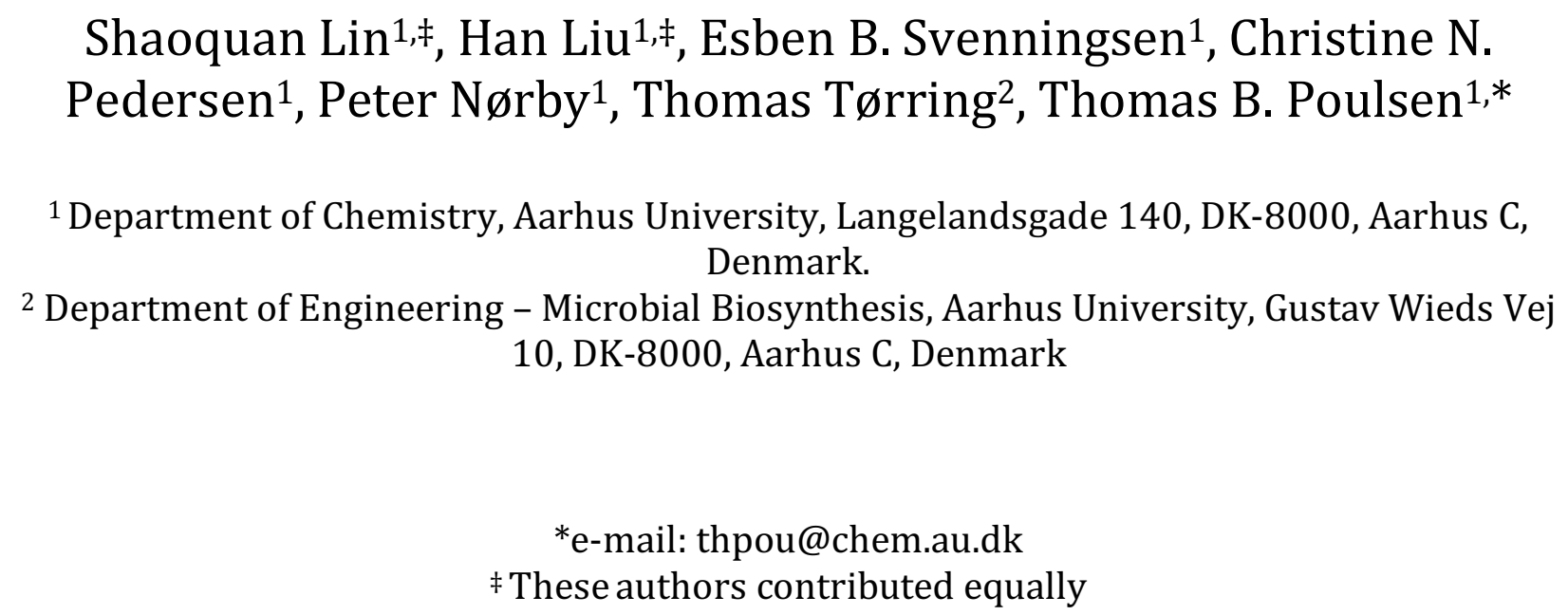


Abstract

The polyether ionophores are complex natural products capable of transporting cations across biological membranes. Many family members possess highly potent antimicrobial activity and a few selected compounds have ability to target particularly aggressive cancer cells. Despite these interesting perspectives, a detailed understanding of the cellular mode-of-action of polyether ionophores is generally lacking. In principle, broad mapping of structure-activity relationships across several biological activities could provide mechanistic insights as well as identification of lead structures but access manuscript, we demonstrate that novel polyether ionophores can be constructed by recycling components of highly abundant polyethers. We provide the first examples of synthetically incorporating halogen-functionalized tetronic acids as cation-binding groups into polyether ionophores and we identify analogs with strong anti-bacterial activity and minimal effects on mammalian cells.

\section{Introduction}

The polyether ionophore natural products have been a constant fix-point for organic chemistry since the 1960s. ${ }^{1}$ The daunting complexity of compounds such as monensin, salinomycin, and X-206 challenged the abilities of chemists to identify their precise molecular structures ${ }^{2,3}$ and has served as inspiration for the development of novel synthetic methods $4,5,6,7,8$ and retrosynthetic analysis. ${ }^{9}$ Elegant syntheses of members of this superfamily ( $>100$ molecules) of natural products have been reported, the majority during the $1980-1990$ s. $^{10,11,12}$ Since then, the raison d'être of natural product synthesis has changed substantially: Ideality in synthesisdesign has become a fulcrum for methodological innovation ${ }^{13,14}$ which has also inspired remarkably efficient routes to members of the polyether ionophores. ${ }^{12,15,16,17}$ 
53 Through strategic integration ${ }^{18}$ of complex molecule synthesis with studies of biological

54 mechanisms, the field of synthesis can catalyze new discoveries within the life sciences.

55 Diversity oriented synthesis, ${ }^{19}$ biology oriented synthesis, ${ }^{20}$ analogue oriented synthesis, ${ }^{21}$

56 diverted total synthesis, ${ }^{22}$ complexity-to-diversity-strategies, ${ }^{23}$ and pharmacophore-directed

57 retrosynthesis ${ }^{24}$ are all different strategic flavors directed towards generating innovative

58 complex structures with potential pharmacological utility. ${ }^{25,26}$

59 The polyether ionophores have thus far escaped attention from efforts that seek to harness

60 their complex structures as fundamental entities of diversity. ${ }^{2,27}$ There may be several reasons

61 for this, but the most important is likely that these compounds are typically considered

62 biologically uninteresting as the perturbation of ion gradients is thought to result in pleiotropic

63 effects on cellular systems. At least in eukaryotic cells, this highly simplistic view of the activity

64 of polyether ionophores is almost certainly deceptive: we do not really know in which of the

65 many endomembranes ionophores operate and which ions they transport. In fact, recent

66 discoveries concerning the biological activity of salinomycin (Sal), ${ }^{28}$ a canonical potassium-

67 ionophore and surprising selective inhibitor of stem-like cancer cells, ${ }^{29}$ suggest that the

68 compound does not even act as an ionophore, but instead sequesters iron in lysosomes which

69 can trigger a type of regulated oxidative cell death known as ferroptosis/oxytosis ${ }^{30}$ or directly

70 bind protein targets as was recently shown with nucleolin. ${ }^{31}$

71 The main feature of polyether ionophores is their antibiotic activity and they are extensively

72 applied in the agricultural industry to control parasitic infections in poultry and as growth

73 promoters in ruminating animals. ${ }^{32,33}$ The latter effect presumably is due to remodeling of the

74 rumen microbiota by the ionophores. Importantly, studies show that polyether ionophores do

75 not display cross-resistance with other major antibiotics and are therefore active in drug-

76 resistant bacterial strains ${ }^{34}$ although their activity is currently restricted to gram-positive

77 strains. The lack of gram-negative activity is not mechanistically understood. As antibiotic 
resistance continues to spread, agents such as the colistins, that were previously shelved due

79 to safety issues, have now been reintroduced to the clinic. We suggest that it is due diligence to seriously consider the antibiotic potential that may lie in the polyether ionophores ${ }^{34}$ and that

81 the field of synthesis should consider how we can deliver truly novel molecules within this 82 class.

83 Here, we outline an approach that can be used to prepare numerous novel polyether 84 ionophores and which takes advantage of two key aspects of this class of compounds: 1) the 85 availability of selected members - the feedstock polyether ionophores e.g. lasalocid, 86 salinomycin, monensin - on a massive scale and 2) the overall structure of polyethers being 87 essentially a series of connected "modules" (Figure 1a). We suggest that by disassembling these 88 modules and then re-combining them with material made through total synthesis, we will be 89 able to access - in a concise manner - an interesting new structural domain related to the 90 natural polyether ionophores (Figure 1a). Some of the resulting compounds will maintain 91 ionophore-activity, but in others, due to subtle structural alterations, this activity will be 92 erased. As the molecular complexity will remain high such "ionophore-dead polyethers" may 93 carry novel biological activities which - with the advent of new methods for small molecule 94 bioactivity-profiling - it is becoming increasingly possible to explore. Importantly, this 95 synthetic approach harnesses the tremendous knowledge generated during prior synthesis 96 efforts for the construction of building blocks and for effecting fragment coupling. ${ }^{10,11,12}$ 

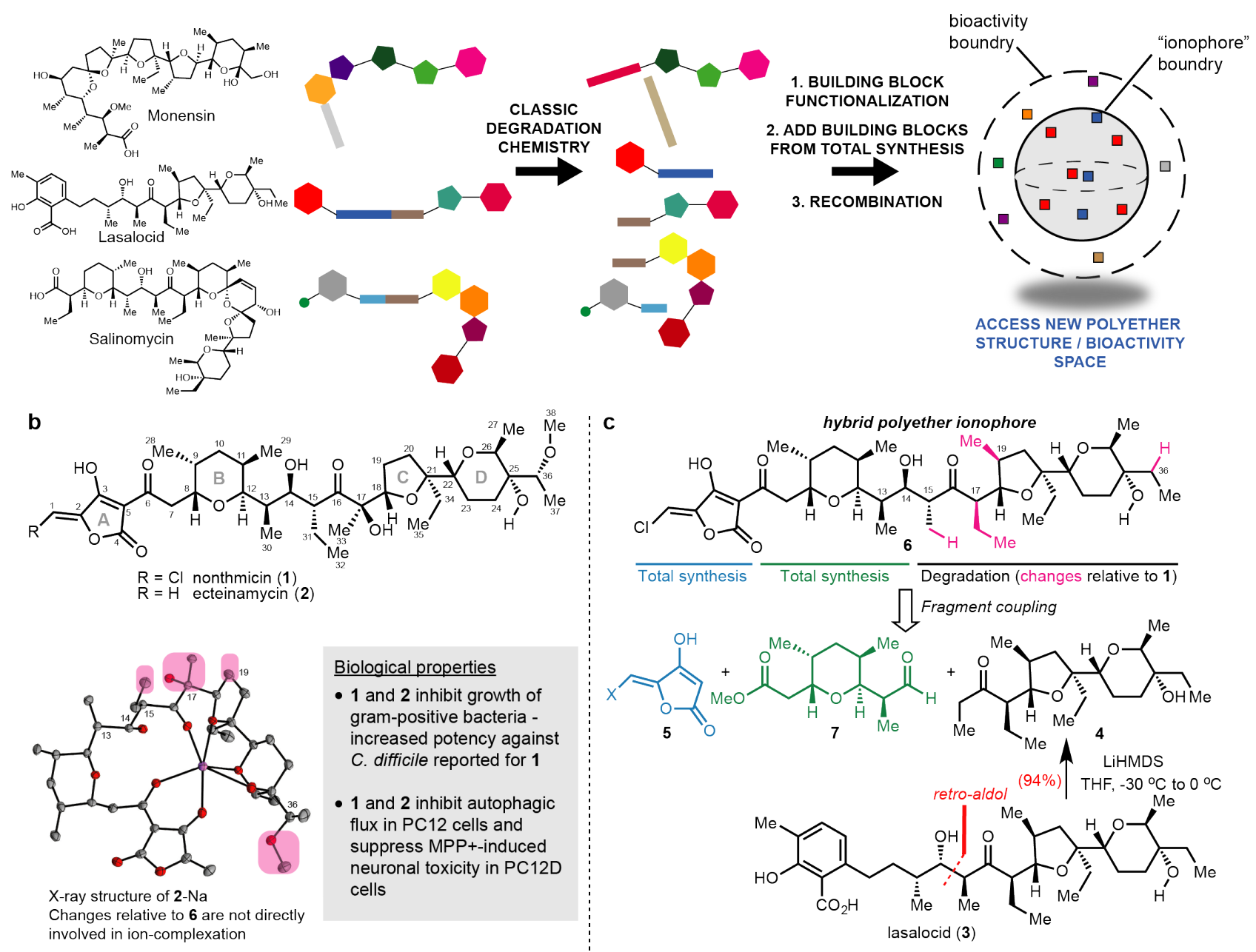

Figure 1 | Accessing structural diversity within the polyether ionophores. (a) Flowchart depicting the overall concept of reconstructing new polyether scaffolds by recycling elements from abundant feedstock polyether ionophores. The resulting "hybrid" molecules (non-red squares) are plotted in a hypothetical structure and bioactivity space to illustrate the relation of these compounds to the natural polyethers (red squares). The compounds that possess strong ionophore activity constitute a sub-space of a larger bioactivity-space that can be explored using hybrid polyethers. (b) Chemical structures and biological properties of polyether ionophores nonthmicin and ecteinamycin. The X-ray structure ${ }^{35}$ depicts ecteinamycin bound to a single sodium-ion and chemical groups on the hydrophopic periphery that have been altered in the target hybrid polyether 6 have been circled in pink. No crystal structure of nonthmicin is available. (c) Chemical structure of the hybrid polyether $\mathbf{6}$ and 
109 indication of the required fragments and the origin of these fragments. The main fragment,

110 ketone 4, can be obtained in a single synthetic step from lasalocid.

\section{Results}

113 Degradation of abundant polyether ionophores as the foundation of diversity synthesis 114 of complex polyethers

115 To provide a proof-of-concept example, we placed our focus on a novel polyether ionophore, 116 nonthmicin (1) (Figure 1b), recently reported to possess several types of interesting biological 117 activities including antibiotic and neuroprotective activity. ${ }^{35}$ Nonthmicin is of particular 118 interest also for structural reasons as this natural product features an unprecedented 119 chloromethylidene tetronic acid building block, that comprise the cation-binding group of the 120 molecule. Another compound, ecteinamycin (2), which differs from 1 only by the absence of the 121 chlorine-atom was reported almost simultaneously by the Bugni lab to be a potent anti122 clostridial antibiotic (Figure $1 \mathrm{~b}$ ). ${ }^{36}$ As we carefully inspected the structure of $\mathbf{1}$ and $\mathbf{2}$, we 123 noticed that the eastern portion (the C-D rings) displayed significant similarity to lasalocid (3) 124 which is available on multi-kg scale. Based on knowledge generated during the classic 125 structure-elucidation studies and then total synthesis of $3,37,38$ we postulated that we could first 126 liberate ketone 4 through a retro-aldol reaction and then develop a short and convergent route 127 to advanced analogs of $\mathbf{1}$ (Figure 1c). Furthermore, inspection of the published X-ray crystal 128 structure of $2-\mathrm{Na}^{35}$ indicated that none of the resulting structural changes (pink in Figure 1b129 c) would directly perturb coordination of the metal ion, at least from the solid-state structure. 130 If successful, this approach would first of all test the fundamental question if swapping modules 131 from different polyether ionophores would even be compatible with sustained antibiotic 132 activity of the resulting hybrid molecules, with $\mathbf{6}$ as the initial target structure. 
133 We started our studies by optimizing the retro-aldol reaction of $\mathbf{3}$ and found that exposure to 134 LiHMDS at low temperature could result in the formation of ketone 4 in excellent yield (94\%).

135 This reaction has been carried out on $>10$ gram scale which underscores the high availability 136 of an advanced building block such as $\mathbf{4}$. We next focused our attention on the preparation of 137 the two remaining building blocks, tetrahydropyran-derivative $\mathbf{7}$ and the challenging 138 halomethylidene tetronic acid moiety $\mathbf{5}$ found in both $\mathbf{6}$ and $\mathbf{1}$.

140 Construction of tetrahydropyran building block

141 The preparation of the targeted tetrahydropyran-derivative was started from (-)-2,4142 dimethylglutaric acid (+)- $\alpha$-methylbenzylamine salt $(9)^{39,40}$ (Figure 2). This salt was readily 143 processed to the diol, which underwent mono-TBS protection followed by TEMPO/PhI(OAc) 2 144 oxidation $^{41}$ to afford aldehyde $\mathbf{1 1}$. We initially proposed that the target building block could be 145 constructed via an intramolecular oxa-Michael reaction ${ }^{42}$ following initial cross-aldol coupling 146 and Horner-Emmons reaction. However, only a trace of the cyclization product was observed 147 and this route was eventually abandoned. Inspired by the Guindon's Narasin fragment 148 synthesis, ${ }^{43}$ we envisioned that the Mukaiyama aldol addition of a silylketene acetal to an 149 oxocarbenium intermediate could also deliver the desired tetrahydropyran-derivative. 150 Towards this end, aldehyde 11 first underwent a $\mathrm{CrCl}_{2}$-catalyzed Nozaki-Hiyama-Kishi 151 crotylation reaction ${ }^{44}$ followed by the cleavage of the silyl ether with $\mathrm{HOAc} / \mathrm{THF} / \mathrm{H}_{2} \mathrm{O}$ and 152 TEMPO/PhI(OAc) 2-promoted lactone formation ${ }^{45}$. This afforded an inseparable diastereomeric 153 mixture $(1.8: 1,65 \%$ isolated yield) of lactone $\mathbf{1 2}$ which was reduced by DIBAL-H to deliver the 154 lactol that was trapped in situ with $\mathrm{Ac}_{2} \mathrm{O}$ to afford the corresponding acetate. At this stage, the major diastereomer $\mathbf{1 3}$ - ultimately found to be the desired configuration at C12 and C13 could be isolated in $52 \%$ yield. Using $\mathrm{BF}_{3} \cdot \mathrm{OEt}_{2}$ as the Lewis acid, $\mathbf{1 3}$ was then exposed to ((1methoxyvinyl)oxy)trimethylsilane at low temperature which provided methyl ester $\mathbf{1 4}$ as a 
single diastereomer (confirmed by X-ray) in excellent yield. Finally, ozonolysis of $\mathbf{1 4}$ followed by reductive work-up with triphenylphosphine generated aldehyde 7 (Figure 2).
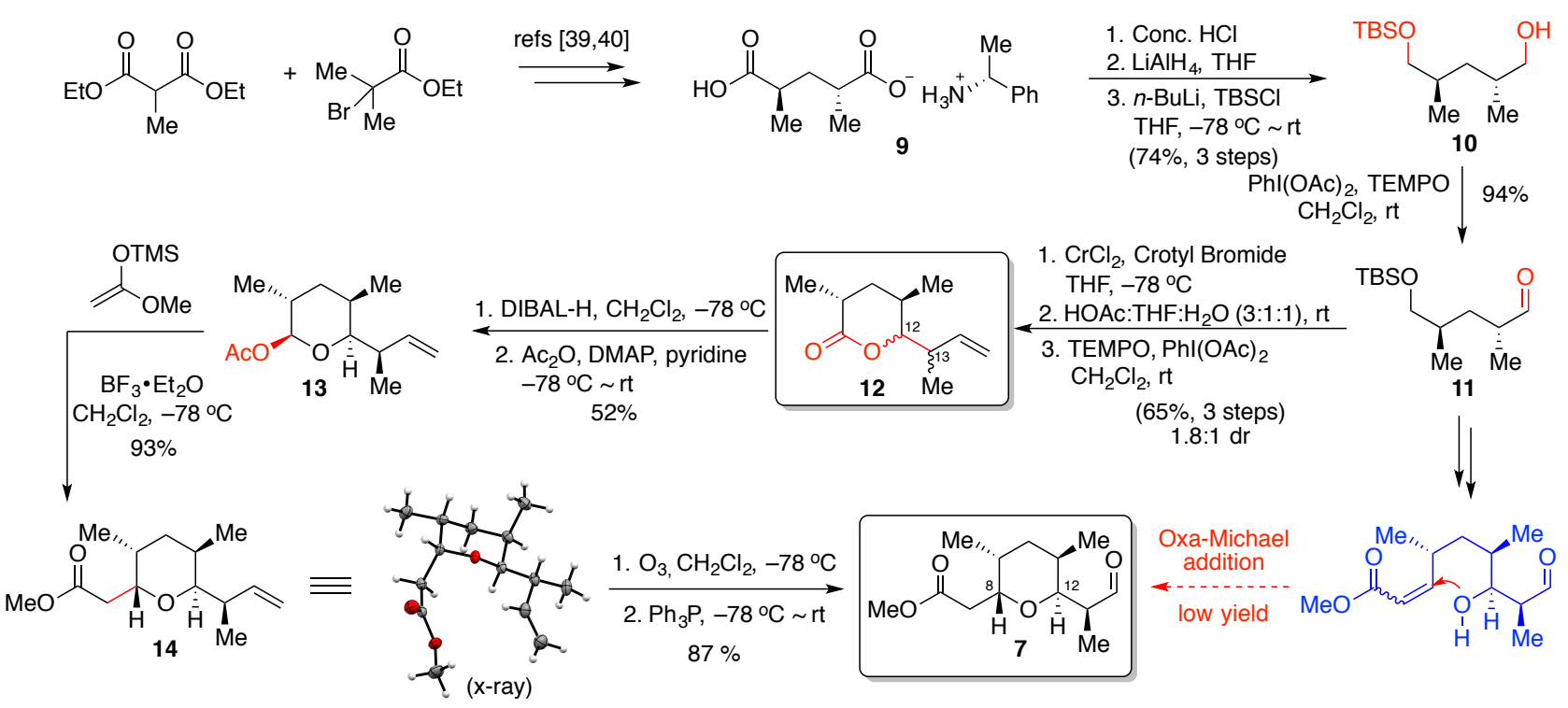

Figure 2 | Stereoselective synthesis of tetrahydropyran (THP) building block 7. Two C-C coupling reactions are used to construct the stereocenters at C12 and C8, the latter being a highly selective addition of a silyl ketene acetal to the oxacarbenium-ion derived from $\mathbf{1 3}$ to generate the desired trans-C8,C12 relative configuration. In turn, the sequence was initiated from optically pure salt $\mathbf{9}$, which is accessible via a known procedure. An alternative route to closure of the THP-ring via an oxa-Michael cyclization failed. $\mathrm{THF}=$ tetrahydrofuran, $\mathrm{TBSCl}=$ tert-butyldimethylsilyl chloride, TEMPO $=$ (2,2,6,6-tetramethylpiperidin-1-yl $)$ oxyl, DMAP $=$ $N, N$-dimethylpyridine-4-amine, DIBAL-H = diisobutylaluminium hydride.

\section{Synthesis of the halomethylidene tetronic acid building block}

As the most intriguing structural subunit of nonthmicin and 6, the 3-acyl-5-chloromethylidene tetronic acid became the next focus. With the overall aim to facilitate structural diversity within the polyether ionophores, the ideal approach to this building block should also allow access to other variants such as the methylidene and bromomethylidene species (Figure 3a). Although 
176 the construction of this small and densely functionalized unit has not previously been realized, 177 published syntheses of natural products containing the nonhalogenated version provide 178 precious lessons (Figure $3 \mathrm{~b}$ ). ${ }^{40-43}$ We opted not to pursue strategies based on organolithium 179 reagent addition ${ }^{42}$ due to the demand of fully protected coupling partners and the uncertain 180 stability of the chlorovinyl moiety to organolithium chemistry. Likewise, approaches based on 181 the Eschenmoser methenylation ${ }^{43}$ were not considered due to unavailability of the chlorinated 182 version of the reagent. Mindful of the presumed lability of the halomethylidene species and the 183 multiple functional groups present in the coupling partner, we selected a DCC-mediated late184 stage coupling as the most appealing strategy ${ }^{41}$ and we therefore decided to target the tetronate 185 building blocks bearing an easily-removable protecting group (TMSE). After a series of 186 unsuccessful attempts (direct $\mathrm{NMe}_{2} / \mathrm{Cl}$ exchange, construction of organotin or organoselenium 187 intermediates, see Supporting Information Figure S1 for more details), we realized the 188 synthesis of the halomethylidene tetronate via a formal C-H halogenation approach (Figure 3c). 189 The $O$-TMSE protected tetronate 19 was prepared via intramolecular Wittig cyclization ${ }^{41}$ from 190 trityl protected $\alpha$-hydroxyl TMSE ester $\mathbf{1 7}$ and the Bestmann reagent, and the methylidene 191 group was installed via MsCl-mediated elimination. The formal $\mathrm{C}-\mathrm{H}$ halogenation was then 192 facilitated by dichlorination $\left(\mathrm{KMnO}_{4}-\mathrm{TMSCl}^{44} /\right.$ dibromination $\left(\mathrm{Br}_{2}\right)^{45}$ of methylidene tetronate 193 and subsequent elimination (DBU) to furnish the target halomethylidene tetronates $\mathbf{8 a}$ and $\mathbf{8 b}$ 194 with desired (Z)-configuration. 


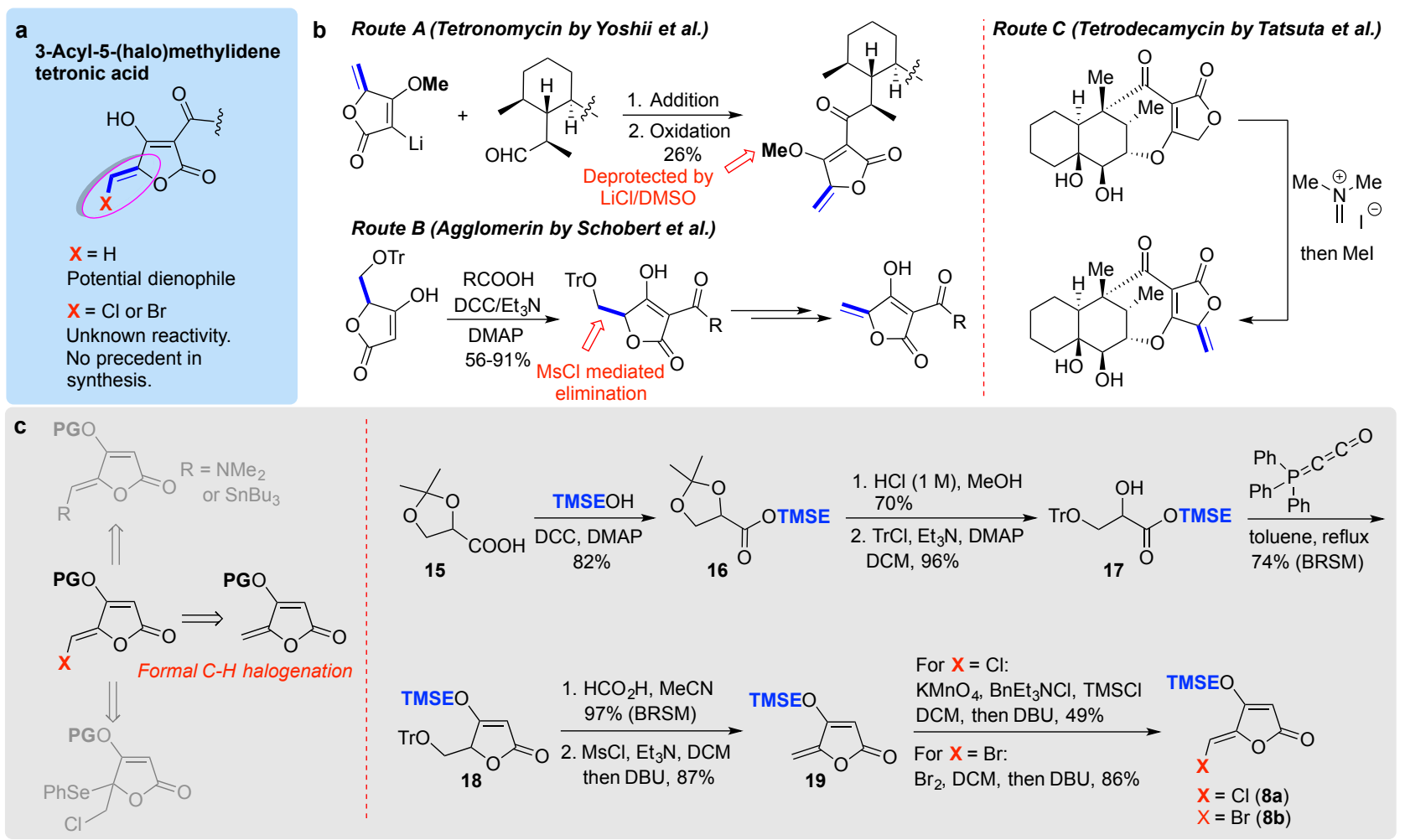

Figure 3 | Development of a synthesis of TMSE-protected 5-(halo)methylidene tetronic acid.

(a) Chemical structure of the targeted 3-acyltetronic acid-derivatives found in nonthmicin/ecteinamycin and $\mathbf{6}$. No previous syntheses of the halogenated variants have been reported. (b) Examples of known methods used to prepare non-halogenated variants. (c) From several synthesis strategies attempted (see also Figure S1, supporting information) a formal C$\mathrm{H}$ halogenation of protected 5-methylidene tetronic acid was developed. Construction of the required TMSE-protected 5-methylidene precursor 19 for these reactions was carried out in 6 steps from the commercial racemic acetonide-protected glycerate 15. This sequence allowed for preparation of both the chlorine and bromine-variants (8a and $\mathbf{8 b})$.

\section{Aldol Fragment coupling}

208 With access to the required building blocks, we initiated the fragment coupling sequence.

209 Analysis of the composition of the stereotriad at C13-C15 in 6 suggests that the desired configuration could be achieved via the effectuation of an anti-aldol reaction with Felkin-

211 control of the secondary alcohol at C14. This type of stereocontrol is usually reinforcing ${ }^{46}$ 
212

213

214

215

216

although in the present case, due to the stereogenic center at C17, double stereodifferentiation in the aldol reaction is required. ${ }^{47}$ We first attempted formation of the $(E)$-boron enolate from 4 or the C25-OTES protected derivative 21 using $(c \mathrm{Hex})_{2} \mathrm{BCl}_{-\mathrm{NEt}_{3}}$ but useful conversion to the enolate could not be achieved. In fact, the only known aldol reactions using $\mathbf{4}$ were carried out in the classic syntheses of lasalocid $\mathbf{3 4}$ and utilized in situ formation of the zinc-enolate from 4 which generates preferentially the configuration found in $\mathbf{3}$ - also anti-aldol-Felkin - and which differs from the configuration needed to make 6 at all of the three stereocenters. Although this aldol coupling utilized a different aldehyde compared to 7, we evaluated the possibilities for favoring the desired aldol product as being low. Consequently, we decided to instead rely on the Lewis acid catalyzed Mukaiyama aldol reaction which is known to maintain Felkinselectivity. ${ }^{48}$ Importantly, double stereodifferentiation in Mukaiyama aldol reactions is established from classic studies by Evans ${ }^{49}$ thus providing a theoretical framework for the analysis of the key fragment coupling reaction. Despite the lack of very closely related reactions in the literature, we expected that formation of the desired anti-aldol isomer $(14 R, 15 R$; anti 15,17-Me↔Et) would still be challenging due to the intrinsic preference for syn-aldol products in the Mukaiyama-aldol reaction and the combined diastereofacial bias from the stereocenters already present in aldehyde $\mathbf{7}$ and ketone $\mathbf{4}$. Formation of the anti-aldol products would demand use of the $(Z)$-silylenolate, whereas the corresponding $(E)$-enolate could be expected to reinforce the formation of a syn-aldol product $(14 R, 15 S$; syn $15,17-\mathrm{Me} \leftrightarrow \mathrm{Et})$. Our first attempts at enolizing ketone $\mathbf{4}$ afforded some surprising results: While the (Z)-TES-enolate 20a could be readily formed with excess TESOTf and 2,6-lutidine with concomitant protection of the tertiary alcohol at $\mathrm{C} 25$, formation of the corresponding $(E)$-enolate could not be accessed cleanly (Figure 4a). After extensive experimentation, we found that substitution of 2,6-lutidine with less hindered pyridine and inverting the sequence of reagent addition (pyridine added to a pre-equilibrated solution of C25-OTES protected ketone $\mathbf{2 1}$ and TESOTf) could afford a nearly 
237 1:1 mixture of the $(Z) /(E)$-TES-enolates $(\mathbf{2 0 a} / \mathbf{2 0 b})$ which could be partially separated by flash 238 chromatography. Gratifyingly, upon exposure of the enolates to aldehyde 7 at low temperature 239 in the presence of $\mathrm{BF}_{3} \bullet \mathrm{OEt}_{2}$, aldol coupling proceeded in excellent yield (Figure 4b). Although 240 we could detect formation of all four putative aldol diastereomers by TLC (P1-P4 based on 241 silical gel mobility), the reaction using an enriched (ratio 1:2.3 Z/E) (E)-TES-enolate was highly 242 selective for the P3-isomer (P2: 7\%, P3: 81\%) whereas the pure (Z)-TES-enolate afforded a 243 mixture of P2 and P3 (P2: 56\%, P3: 30\%). Subsequent stereochemical assignment of the 244 respective compounds by X-ray crystallography revealed P3 to be the $(14 R, 15 S)$-configured 245 product (23) in accord with the above analysis and P2 to be the desired isomer $(14 R, 15 R)(22)$. 246

\section{End game coupling and purification}

248 Both aldol products (22 and 23) underwent a two-step deprotection sequence, involving first 249 Olah's reagent to remove the C25-OTES group and then trimethyltin hydroxide to cleave the 250 methyl ester (Figure 4c).50 The latter conditions were found to be critical to avoid retro-aldol 251 cleavage. 
a<smiles>CCOC(=O)OCCOc1ccc(OCC)cc1</smiles>
$\mid \begin{gathered}\text { TESOTf, 2,6-lutidine } \\ \mathrm{CH}_{2} \mathrm{Cl}_{2},-78^{\circ} \mathrm{C} \sim-10^{\circ} \mathrm{C} \\ 82 \%\end{gathered}$

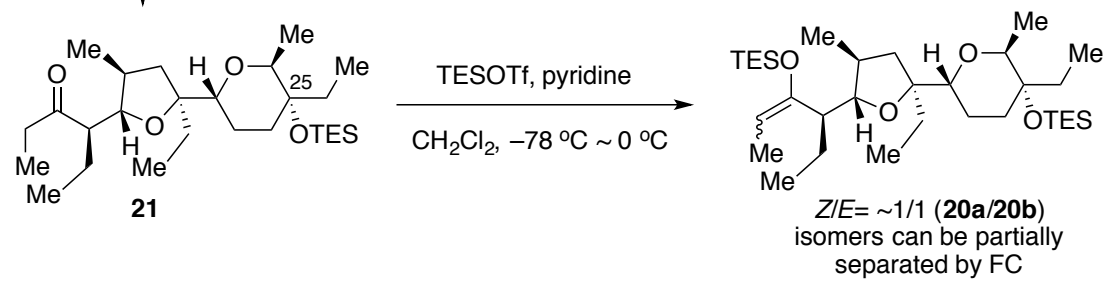

b

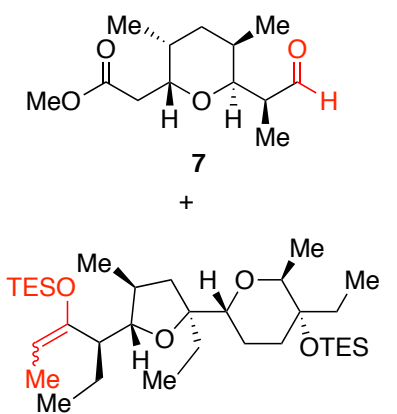

$20 \mathrm{a} / 20 \mathrm{~b}$

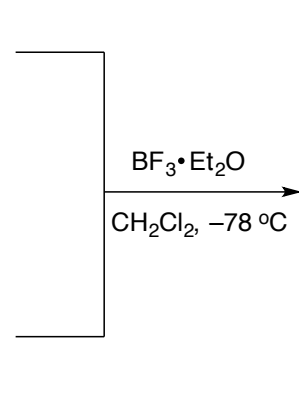

$\underset{\mathrm{CH}_{2} \mathrm{Cl}_{2},-78{ }^{\circ} \mathrm{C}}{ }$

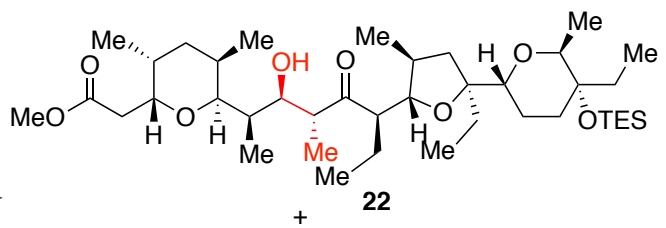

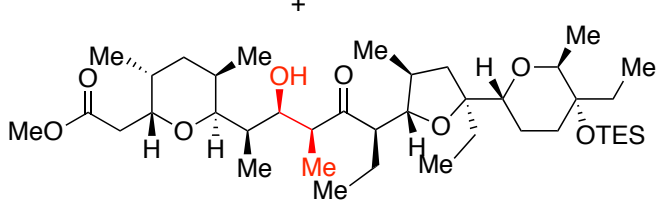

$30 \%$

$81 \%$

c

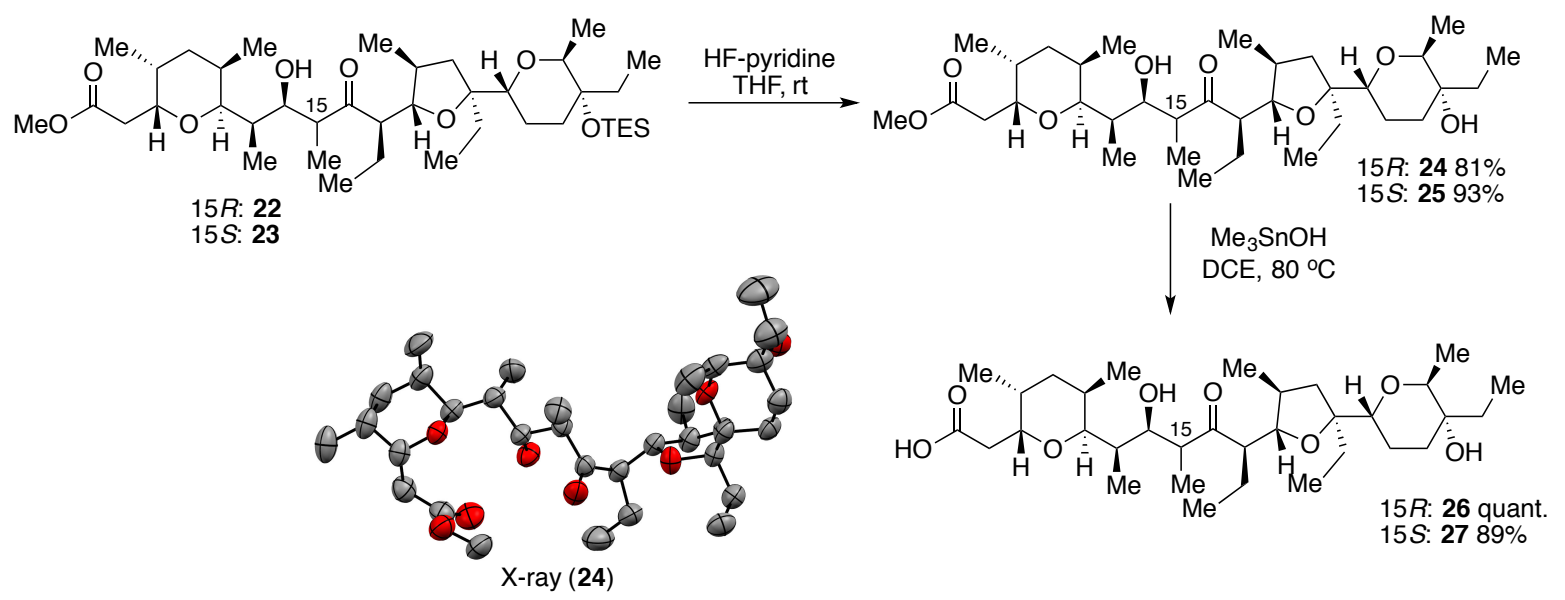

253 Figure 4 | Fragment-coupling via boron trifluoride-mediated Mukaiyama-aldol reaction. (a)

254 The (Z)-TES-enolate 20a could be readily obtained, but special procedures had to be developed 255 to access mixtures of $(E)$ - and $(Z)$-TES-enolates. Purification could be used to further enrich the (E)-TES-enolate 20b. (b) Aldol reaction affords two major products (22 and 23) depending on

257 the configuration of the silyl-enolate derived from ketone 4. Compound 22 was confirmed by 
X-ray analysis of derivative $\mathbf{2 4}$ to be the initially targeted aldol-product (c) Both aldol products

22 and 23 could be processed towards the final fragment coupling in two high-yielding steps. TESOTf = triethylsilyltrifluoromethanesulfonate, DCE = 1,2-dichloroethane.

With the desired acid fragments (26 and 27) and $O$-TMSE protected tetronates (19 and 8a-b) in hand, we started to investigate the final fragment coupling reaction. After TBAF-mediated deprotection of the $O$-TMSE group on $\mathbf{8 a}$ and simple extraction, the crude tetronic acid was submitted to DCC coupling with carboxylic acid 26 (Figure 5a). Fortunately, the desired product 6 was smoothly formed in 24 hours with full conversion of 26, and 59\% yield (as the sodium salt, 6-Na) was obtained by preparative HPLC using MeCN-10 mM NH $\mathrm{NCO}_{3}$ as eluent. ${ }^{35}$ It is worth to note that the sodium salt (formed by subsequent $\mathrm{NaHCO}_{3}$ treatment and extraction) show much better solubility in organic solvents than the acid form, which indicates the formation of a lipophilic complex, a featured property of polyether ionophores. Encouraged by this result, the bromine-analog 29 and hydrogen-analog $\mathbf{3 0}$, as well as the chlorine-analog 31 bearing 15- $(S)$ configuration, were synthesized following the same procedure in $42-58 \%$ yields (Figure 5a). We managed to prepare crystals that were suitable for X-ray diffraction from both 6,29 , and 31 and the resulting structures revealed the formation of a cage-like structure by the "naturally-configured" $15-(R)$ analogs 6 and 29 while a dimeric complex was formed by the corresponding 15-(S)-configured compound 31. This clearly indicates the critical role played by evolutionary conformational design ${ }^{51}$ on the cation-binding properties of the polyether ionophores. Anticipating that small structural changes would potentially have a large impact on the biological activities, we finally generated an additional derivative of $\mathbf{3 2}$ (Figure 5a) by performing an anti-selective Evans-Saksena ${ }^{52}$ reduction of the carbonyl group in $\mathbf{2 6}$ followed by coupling with the tetronic acid derived from 8a (Figure S2). 
a
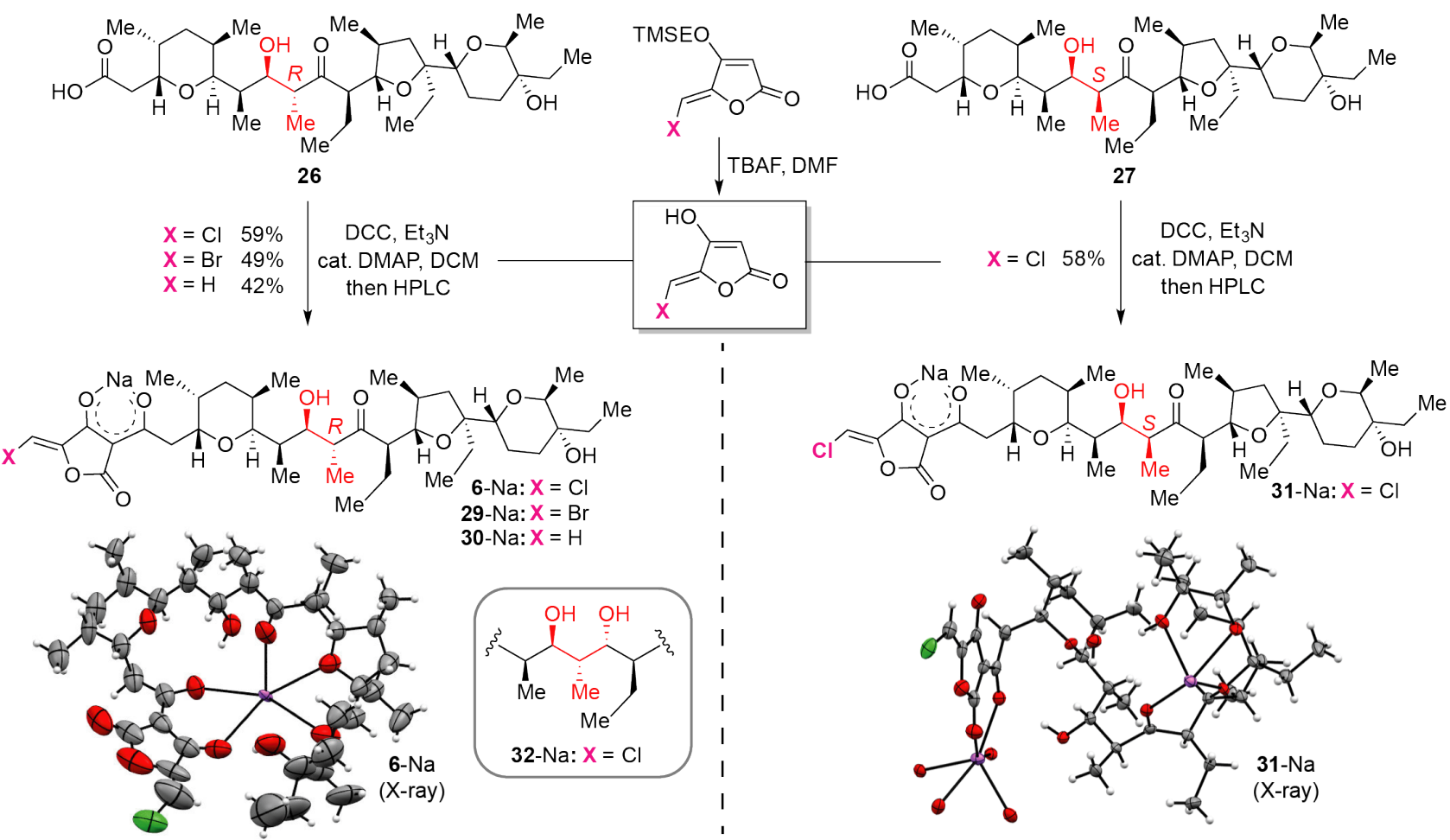

$30-\mathrm{Na}: \mathrm{X}=\mathrm{H}$

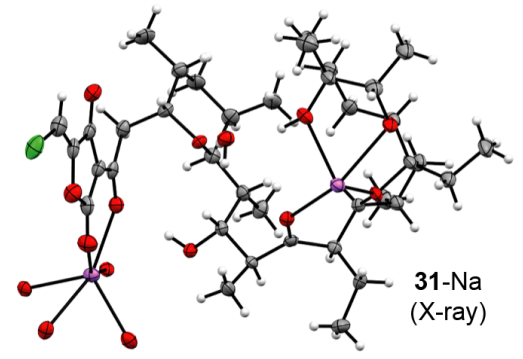

b

\begin{tabular}{|cccccccccc|}
\hline strain & \multicolumn{10}{c|}{$\mathrm{MIC}(\mathrm{\mu g} / \mathrm{mL})$} \\
\cline { 2 - 9 } & Lasalocid & $\mathbf{6}$ & $\mathbf{2 9}$ & $\mathbf{3 0}$ & $\mathbf{3 1}$ & $\mathbf{3 2}$ & salinomycin & vanco \\
S. aureus & 2 & 8 & 4 & 32 & $>32$ & 8 & 2 & 1 \\
$\begin{array}{c}\text { S. aureus MRSA USA 300 je2 } \\
\text { S. aureus ATCC 29213 }\end{array}$ & 2 & 8 & 8 & 32 & $>32$ & $8-16$ & 4 & 1 \\
$\begin{array}{c}\text { P. auroginosa } \\
\text { E. coli }\end{array}$ & $4-8$ & 8 & 8 & 32 & $>32$ & $8-16$ & 2 & 0.5 \\
& $>32$ & $>32$ & $>32$ & nd & $>32$ & nd & nd & $>32$ \\
cell line & & $>32$ & $>32$ & nd & $>32$ & nd & nd & $>32$ \\
U2OS & Lasalocid & $\mathbf{6}$ & $\mathbf{2 9}$ & $\mathbf{3 0}$ & $\mathbf{3 1}$ & $\mathbf{3 2}$ & salinomycin & vanco \\
MCF-7 & $10 \pm 0.8$ & $7.5 \pm 0.3$ & $6.8 \pm 0.6$ & $22 \pm 0.8$ & $36 \pm 2$ & $5.9 \pm 1.1$ & $5.8 \pm 0.8$ & nd \\
& $6.3 \pm 2.2$ & $16 \pm 2$ & $13 \pm 1$ & $26 \pm 2$ & $42 \pm 7$ & $6.8 \pm 0.6$ & $4.5 \pm 1.5$ & nd \\
\hline
\end{tabular}

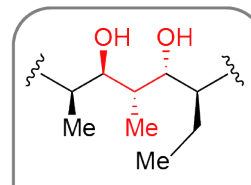

32-Na: $\mathrm{X}=\mathrm{Cl}$

Figure 5. Final coupling sequence and biological activities of the hybrid tetronate polyethers.

(a) Mild conditions were developed for effecting the coupling of unprotected (halo)methylidene tetronates to acids $\mathbf{2 6}$ or $\mathbf{2 7}$. The structures of $\mathbf{6 , 2 9}$ (see supporting information) and 31, all as the sodium salts, were solved by X-ray diffraction. (b) Anti-bacterial activity and effects on mammalian cell viability were evaluated for all compounds using canonical polyether ionophores (salinomycin and lasalocid) and vancomycin as the controls. For full inhibition curves see supporting information Fig. S3 and Fig. S4. MIC-values is mean $(N=3)$ and mammalian cell viability is mean $\pm \mathrm{sd}(N=3)$. nd $=$ not determined. 


\section{Antibacterial and anti-proliferative activity of hybrid tetronate polyethers}

293 In order to probe the biological properties of the hybrid polyethers, we first performed an 294 evaluation of their anti-bacterial activity against a small panel of $S$. aureus strains (gram295 positive) and two different gram-negative strains (P. auroginosa and E. Coli). To our delight, 296 these experiments showed that compounds $\mathbf{6}$ and $\mathbf{2 9}$ did indeed maintain antibacterial activity 297 with a potency comparable to lasalocid and salinomycin against both wild-type and drug298 resistant S. aureus (Figure 5b and Fig. S3). Comparing the activity of 6, 29, and 30, it is clear 299 that the halogen augments the contribution of the tetronic acid as the methylene-analog $\mathbf{3 0}$ was 300 significantly less active. Compound 31, being epimeric to 6 at C15, was completely devoid of 301 activity (MIC $>32 \mu \mathrm{g} / \mathrm{mL}$ ), while 32 was equally active to 6 . None of the compounds were active 302 against gram-negative strains. Next, we evaluated inhibitory activity against human cancer cell 303 lines (U2OS and MCF7, Figure 5b) which afforded micromolar IC 50 's of all the compounds. We 304 noted however distinctively more shallow inhibition curves for the natural products, especially 305 salinomycin (Figure S4), indicating that these compounds perturb mammalian cells over a 306 larger span of concentrations.

308 Bioactivity analysis using morphological profiling

309 Modulation of cell viability is a coarse measure of the biological activity of a small molecule. To 310 provide a more nuanced analysis of the activities of the polyethers in mammalian cells, we 311 subjected all compounds to morphological profiling 53,54 in U2OS osteosarcoma cells. This 312 image-based method can generate bioactivity profiles of small molecules in an unbiased 313 manner that can be used statistically to reveal mechanistic similarities. Given the limited 314 detailed knowledge about the activity of polyether ionophores in mammalian cells, this 315 approach could potentially illuminate how structural changes impact the overall cellular 316 perturbation. 
a

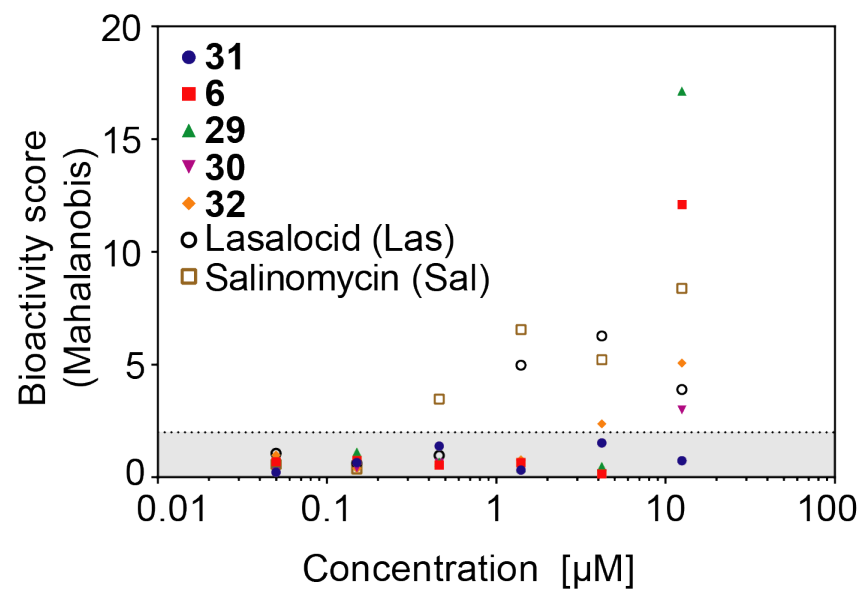

C

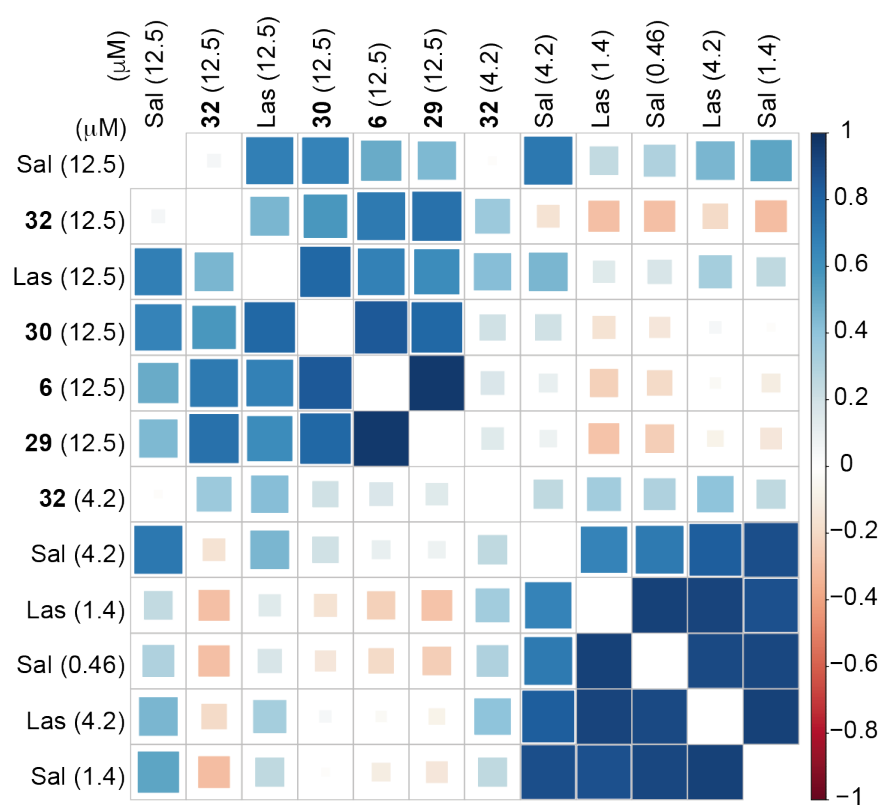

b

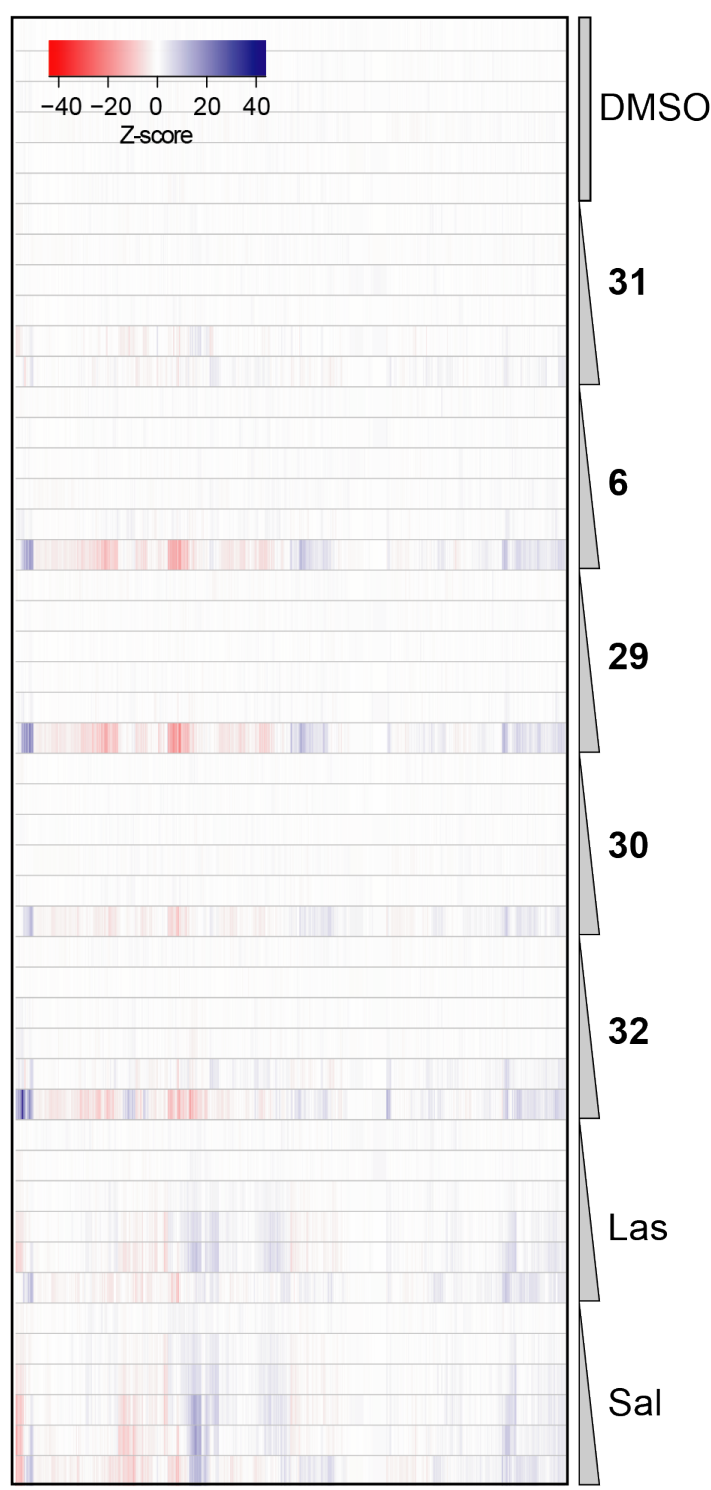

Features (total 1476)

319 Figure 6. Morphological profiling. (a) Bioactivity scores as measured by the Mahalanobis 320 distance to DMSO control. The grey area (Mahalanobis distance $<2$ ) indicates inactivity. Sal and

321 Las show activity at a lower concentration than the hybrid ionophores. (b) Heatmap of full 322 morphological profiles. The color corresponds to the Z-score calculated from averaged profiles. 6, 29, 30 and 32 shows similar profiles at the highest concentration $(12.5 \mu \mathrm{M})$. Note that the 324 shown DMSO treatments are kept separate from the other DMSO controls used in the normalization step. (c) Pearson correlation matrix of active compounds ordered by hierarchical clustering. Two clusters with distinct bioactivities are formed, one containing lower 
concentrations of Las and Sal and one containing high concentrations of both hybrid

328 ionophores and Las and Sal. The color and size of the squares indicates the Pearson correlation 329 coefficient.

331 All compounds were tested at six different concentrations (0.05-12.5 $\mu \mathrm{M})$ and we used 332 salinomycin and lasalocid as controls. First, we calculated the Mahalanobis distance for all 333 compound treatments to DMSO controls as an overall measure for above-background activity 334 in the assay (Figure 6a and Figure S5-7). Using a rather strict threshold (see Supporting 335 Information for details and Fig. S6), hybrid polyethers 6, 29 and 30 were scored inactive at all 336 but the highest concentration $(12.5 \mu \mathrm{M})$, compound $32 \mathrm{had}$ an active profile also at $4.2 \mu \mathrm{M}$, and 337 epimer $\mathbf{3 1}$ was inactive at all tested concentrations.

338 In contrast to the hybrid polyethers, salinomycin and lasalocid were both active at lower 339 concentrations (by 9-27 fold, Figure 6a). The full bioactivity profiles were plotted (Figure 6b) 340 and a Pearson correlation matrix was calculated for all compound treatments exceeding the 341 activity threshold (Figure 6c). We were quite surprised by the outcome of this analysis: The 342 activity profiles of salinomycin and lasalocid over several concentrations were clustered $(P$ 343 0.83-0.94) whereas the hybrid ionophores - at the highest concentration - formed a distinct 344 cluster (Figure 6c). Interestingly, high concentrations of both lasalocid and salinomycin also 345 afforded profiles with significant correlations $(P>0.63)$ to this cluster as did a subset of a 346 reference panel of different growth inhibitory compounds (Figure S7) suggestive of a general 347 toxicity profile. In contrast, the bioactivity profiles associated with the first cluster (low 348 concentration Sal and Las) did not show significant correlations with profiles in our reference 349 panel.

350 Given the recent strong interest in the cellular activity of salinomycin ${ }^{29,30,31}$ and the significant 351 difference in both the chemical structures and ionophore-properties associated with 
salinomycin (a K-ionophore as previously mentioned) and lasalocid (a Ca-ionophore), the apparent mechanistic similarity - which is suggested by our data - demands future attention. Another important observation from these experiments is that the hybrid polyethers appear to be more 'silent' in mammalian (U2OS) cells despite having similar anti-bacterial activity compared to lasalocid and salinomycin.

\section{Discussion}

As we consider the potential future role of polyether ionophores in biomedicine the following questions are important: 1) Can polyether ionophores be identified with a sufficiently large therapeutic window to be considered as human antibiotics; 2) Can the activity of these compounds be expanded to also target gram-negative strains; 3) Which aspects of mammalian cell biology can be modulated by polyethers? To answer all of these questions, a large increase in accessible compounds within the overall polyether-class is needed. For instance, systematic tests in expanded bacterial panels may reveal activity patterns that can inform further structural variations and in combination with investigations of cross-resistance to other antibiotics new synthetic lead structures can be identified. The use of unbiased bioactivity profiling in mammalian cells - as we demonstrate here - may both pinpoint polyethers with unusual activity patterns that can be subjected to focused mechanistic investigations as well as variants that appear 'silent' in mammalian cells while maintaining antibacterial activity. Hybrid polyether 29 is a good example of the latter. The compound has a ratio of 0.5 between the average (molar) MIC across the S. aureus strains and the first bioactive concentration in U2OS cells whereas the equivalent numbers for salinomycin and lasalocid are 5.8 and 2.4, respectively. However, we currently do not understand the mechanistic and structural factors that underlie these differences. On a similar note, despite having closely related structures, compounds $\mathbf{6}$ and $\mathbf{2 9}$ are less active (up to 64 fold) compared to the remarkably low MIC-values 
reported for ecteinamycin (2) ${ }^{36}$. The specific reason(s) for this difference is also of strong 378 interest. We e.g. note that in the solid state, the sodium-bound forms of $\mathbf{2}$ and $\mathbf{6} / \mathbf{2 9}$ differ subtly 379 due to the structural variations close to the C17-C18 bond (Figure S8). How these changes affect 380 the relative selectivity and efficiency of ion-transport should be addressed in future studies.

381 In conclusion, it is evident that complex polyethers can affect both eukaryotic and prokaryotic 382 cells in ways that transcend the canonical model of pleiotropic ion-transporters and therefore 383 that a strategic merger of synthesis and biology broadly across this class of compounds is 384 timely. The overall synthesis principle of reusing parts of the abundant polyethers that we 385 outline in this paper - fueled by novel methods (such as MicroED ${ }^{55}$ ) to expedite structural 386 assignment of complex molecules and methods to study mechanisms-of-action - may therefore 387 contribute to the effective resurrection of this whole class of compounds.

\section{Acknowledgements}

390 TBP acknowledges financial support from the Carlsberg foundation (grant CF17-0800) and 391 Independent Research Fund Denmark (Sapere Aude 2 grant 6110-00600A). We are grateful to 392 Eric Jung and Anja Johnbeck for technical assistance with organic synthesis, Anders Bodholt 393 Nielsen for technical assistance with NMR spectroscopy, and Iben Charlotte Stensgaard Jensen 394 for technical assistance with microbiology.

\section{Author contributions}

397 TBP conceived and supervised the study. TBP, SL, and HL designed experiments. SL, HL, and 398 CNP performed organic synthesis. EBS conducted cell biological experiments and analyzed 399 data. TT supervised microbiology experiments and analyzed data. PN carried out x-ray 400 crystallographic analyses. TBP, SL, HL wrote the manuscript with input from all authors. 401 


\section{Competing financial interests}

403 The authors declare no competing financial interests

404

405

406

407

408

409

410

411

412

413

414

415

416

417

418

419

420

421

422

423

424

425

426

427

\section{Methods}

\section{Organic Synthesis}

All reactions were conducted in flame-dried glassware under an atmosphere of argon unless otherwise stated. $\mathrm{CH}_{2} \mathrm{Cl}_{2}, \mathrm{MeCN}$, THF and $\mathrm{PhMe}$ were dried over aluminium oxide via an MBraun SPS-800 solvent purification system. DCE, DMF, MeOH and pyridine were purchased as anhydrous. The dryness of solvents was controlled via Karl Fischer tritration. Reagents were used as received from commercial suppliers unless otherwise stated (Sigma Aldrich, Merck, AK Scientific, and Fluorochem). $\mathrm{Et}_{3} \mathrm{~N}$ and DIPEA were dried by stirring for at least 30 minutes over $\mathrm{CaH}_{2}$ followed by distillation onto preactivated molecular sieves ( $4 \AA$ ). Concentration in vacuo was performed using a rotary evaporator with the water bath temperature at $30{ }^{\circ} \mathrm{C}$, or $40{ }^{\circ} \mathrm{C}$, followed by further concentration using a high vacuum pump. TLC analysis was carried out on silica coated aluminum foil plates (Merck Kieselgel 60 F254). The TLC plates were visualized by UV irradiation and/or by staining with either CAM stain $\left(\left(\mathrm{NH}_{4}\right)_{6} \mathrm{Mo}_{7} \mathrm{O}_{24} \cdot 4 \mathrm{H}_{2} \mathrm{O}(10 \mathrm{~g})\right.$, Cerric ammonium sulfate (4 g), $10 \% \mathrm{H}_{2} \mathrm{SO}_{4}$ (aq., $400 \mathrm{~mL}$ )), ninhydrin stain (ninhydrin (12 g) and AcOH (12 mL) in $n$-butanol $(400 \mathrm{~mL}))$ or $\mathrm{KMnO}_{4}$ stain $\left(\mathrm{KMnO}_{4}(5.0 \mathrm{~g}), 5 \% \mathrm{NaOH}\right.$ (aq., $\left.8.3 \mathrm{~mL}\right)$ and $\mathrm{K}_{2} \mathrm{CO}_{3}(33.3 \mathrm{~g})$ in $\left.\mathrm{H}_{2} \mathrm{O}(500 \mathrm{~mL})\right)$. Molecular sieves were activated by drying in the oven at 120 ${ }^{\circ} \mathrm{C}$ for at least 24 hours, before they were heated in a microwave at maximum power for 2 minute, followed by evaporation of the formed vapour on the high vacuum line. This was repeated 3-4 times, and finished by gently flame-drying the flask containing the molecular sieves. Flash column chromatography (FCC) was carried out using silica gel (230-400 mesh particle size, $60 \AA$ pore size) as stationary phase. Infrared spectra (IR) were acquired on a PerkinElmer Spectrum TwoTM UATR. Mass spectra (HRMS) were recorded on a Bruker Daltonics MicrOTOF time-of-flight spectrometer with positive electrospray ionization, or 
428

429

negative ionization when stated. Nuclear magnetic resonance (NMR) spectra were recorded on a Varian Mercury $400 \mathrm{MHz}$ spectrometer or a Bruker BioSpin GmbH $400 \mathrm{MHz}$ spectrometer, running at 400 and $101 \mathrm{MHz}$ for ${ }^{1} \mathrm{H}$ and ${ }^{13} \mathrm{C}$, respectively. Chemical shifts $(\delta)$ are reported in ppm relative to the residual solvent signals $\left(\mathrm{CDCl}_{3}: 7.26 \mathrm{ppm}{ }^{1} \mathrm{H} \mathrm{NMR}, 77.16 \mathrm{ppm}{ }^{13} \mathrm{C} \mathrm{NMR}\right.$, $\mathrm{CD}_{3} \mathrm{OD}: 3.31 \mathrm{ppm}{ }^{1} \mathrm{H}$ NMR, $49.00 \mathrm{ppm}{ }^{13} \mathrm{C}$ NMR, ${ }^{6} \mathrm{~d}$-DMSO: $2.50 \mathrm{ppm}{ }^{1} \mathrm{H}$ NMR, $39.52 \mathrm{ppm}{ }^{13} \mathrm{C}$ NMR. Multiplicities are indicated using the following abbreviations: $\mathrm{s}=$ singlet, $\mathrm{d}=$ doublet, $\mathrm{t}=$ triplet, $\mathrm{q}=$ quartet, $\mathrm{h}=$ heptet, $\mathrm{m}=$ multiplet, $\mathrm{br}=$ broad. LC-MS and HPLC analysis and purification were performed using a Gilson HPLC system.

For all remaining methods, see the supplementary information.

\section{References}

${ }^{1}$ A. Agtarap, J. Chamberlin, J. W. Pinkerton and L. Steinrauf, J. Am. Chem. Soc., 89, 5737 (1967). 2 Westley, J. ed., (1982). Polyether Antibiotics - Naturally Occurring Acid Ionophores. 1st ed. New York: Marcel Dekker.

${ }^{3}$ Dutton, C. J., Banks, B. J. \& Cooper, C. B. Polyether ionophores. Nat. Prod. Rep. 12, 165-181 (1995).

${ }^{4}$ Nakata, T. et al. A Total Synthesis of Lasalocid A. J. Am. Chem. Soc. 100, 2933-2935 (1978).

${ }^{5}$ Fukuyama, T. et al. Total Synthesis of Monensin. 3. Stereocontrolled Total Synthesis of Monensin. J. Am. Chem. Soc. 101, 262-263 (1979).

${ }^{6}$ Collum, D. B., McDonald, J. H. \& Still, W. C. Synthesis of the Polyether Antibiotic Monensin. 3. Coupling of Precursors and Transformation to Monensin1. J. Am. Chem. Soc. 102, 2120-2121 (1980).

${ }^{7}$ Ireland, R. E., Thaisrivongs, S. \& Wilcox, C. S. Total Synthesis of Lasalocid A (X537A). J. Am. Chem. Soc. 102, 1155-1157 (1980).

${ }^{8}$ Evans, D. A., Bender, S. L. \& Morris, J. Total Synthesis of the Polyether Antibiotic X-206. J. Am. Chem. Soc. 110, 2506-2526 (1988).

${ }^{9}$ Corey, E. J. \& Cheng, X.-M. The logic of chemical synthesis. (Wiley, 1995). 
${ }^{10}$ Faul, M. M. \& Huff, B. E. Strategy and Methodology Development for the Total Synthesis of Polyether Ionophore Antibiotics. Chem. Rev. 100, 2407-2473 (2000).

${ }^{11}$ Song, Z., Lohse, A. G. \& Hsung, R. P. Challenges in the synthesis of a unique mono-carboxylic acid antibiotic, (+)-zincophorin. Nat. Prod. Rep. 26, 560-571 (2009).

${ }^{12}$ Liu, H., Lin, S., Jacobsen, K. M. \& Poulsen, T. B. Chemical syntheses and chemical genetics of carboxyl polyether ionophores: Recent highlights, Angew. Chem. Int. Ed. (2019), doi:

10.1002/anie.201812982

${ }^{13}$ Schwan, J. \& Christmann, M. Enabling strategies for step efficient syntheses. Chem. Soc. Rev. 47, 7985-7995 (2018).

${ }^{14}$ Gaich, T. \& Baran, P. S. Aiming for the ideal synthesis. J. Org. Chem. 75, 4657-4673 (2010).

15 Kasun, Z. A., Gao, X., Lipinski, R. M. \& Krische, M. J. Direct Generation of Triketide Stereopolyads via Merged Redox-Construction Events: Total Synthesis of (+)-Zincophorin Methyl Ester. J. Am. Chem. Soc. 137, 8900-8903 (2015).

16 Wang, G. \& Krische, M. J. Total Synthesis of (+)-SCH 351448: Efficiency via Chemoselectivity and Redox-Economy Powered by Metal Catalysis. J. Am. Chem. Soc. 138, 8088-8091 (2016). 17 Chen, L.-A., Ashley, M. A. \& Leighton, J. L. Evolution of an Efficient and Scalable Nine-Step (Longest Linear Sequence) Synthesis of Zincophorin Methyl Ester. J. Am. Chem. Soc. 139, 4568-4573 (2017).

${ }^{18}$ Huffman, B. J. \& Shenvi, R. A. Natural Products in the 'Marketplace': Interfacing Synthesis and Biology. J. Am. Chem. Soc. 141, 3332-3346 (2019).

${ }^{19}$ Schreiber, S. L. Target-oriented and diversity-oriented organic synthesis in drug discovery. Science 287, 1964-1969 (2000).

20 Wetzel, S., Bon, R. S., Kumar, K. \& Waldmann, H. Biology-oriented synthesis. Angew. Chem. Int. Ed. 50, 10800-10826 (2011).

${ }^{21}$ Könst, Z. A. et al. Synthesis facilitates an understanding of the structural basis for translation inhibition by the lissoclimides. Nat. Chem. 9, 1140-1149 (2017).

22 Wilson, R. M. \& Danishefsky, S. J. Small molecule natural products in the discovery of therapeutic agents: the synthesis connection. J. Org. Chem. 71, 8329-8351 (2006).

${ }^{23}$ Huigens, R. W. et al. A ring-distortion strategy to construct stereochemically complex and structurally diverse compounds from natural products. Nat. Chem. 5, 195-202 (2013).

${ }^{24}$ Abbasov, M. E. et al. Simplified immunosuppressive and neuroprotective agents based on gracilin A. Nat. Chem. 11, 342-350 (2019).

${ }^{25}$ Seiple, I. B. et al. A platform for the discovery of new macrolide antibiotics. Nature 533, 338-345 (2016). 
${ }^{26}$ Richter, M. F. et al. Predictive compound accumulation rules yield a broad-spectrum antibiotic. Nature 545, 299-304 (2017).

${ }^{27}$ Focused analogs of polyether ionophores have been made. See especially ref. 2. A recent example for salinomycin: Antoszczak, M. et al. Biological activity of doubly modified salinomycin analogs - Evaluation in vitro and ex vivo, Eur. J. Med. Chem. 156, 510-523 (2018). 28 Versini, A. et al. Chemical biology of salinomycin. Tetrahedron 74, 5585-5614 (2018). ${ }^{29}$ Gupta, P. B. et al. Identification of selective inhibitors of cancer stem cells by highthroughput screening. Cell 138, 645-659 (2009).

${ }^{30}$ Mai, T. T. et al. Salinomycin kills cancer stem cells by sequestering iron in lysosomes. Nat. Chem. 9, 1025-1033 (2017).

31 Wang, F. et al. Nucleolin Is a Functional Binding Protein for Salinomycin in Neuroblastoma Stem Cells. J. Am. Chem. Soc. 141, 3613-3622 (2019).

32 Chapman, H. D., Jeffers, T. K. \& Williams, R. B. Forty years of monensin for the control of coccidiosis in poultry, Poultry Sci. 89, 1788-1801 (2010).

33 Goodrich, R. D. et al. Influence of monensin on the performance of cattle. J. Anim. Sci. 58, 1484-1498 (1984).

${ }^{34}$ Kevin II, D. A., Meujo, D. A. \& Hamann, M. T. Polyether ionophores: broad-spectrum and promising biologically active molecules for the control of drug-resistant bacteria and parasites. Expert Opin. Drug Discov. 4, 109-146 (2009)

35 Igarashi, Y. et al. Nonthmicin, a Polyether Polyketide Bearing a Halogen-Modified Tetronate with Neuroprotective and Antiinvasive Activity from Actinomadura sp. Org. Lett. 19, 14061409 (2017).

36 Wyche, T. P. et al. Chemical Genomics, Structure Elucidation, and in Vivo Studies of the Marine-Derived Anticlostridial Ecteinamycin. ACS Chem. Biol. 12, 2287-2295 (2017).

37 Westley, J. W., Evans, R. H., Williams, T. \& Stempel, A. Structure of antibiotic X-537A. J. Chem. Soc. $D, 71-72$ (1970).

${ }^{38}$ Westley, J. W., Evans, R. H., Williams, T. \& Stempel, A. Pyrolytic Cleavage of Antibiotic X537A and Related Reactions. J. Org. Chem. 38, 3431-3433 (1973).

39 Gruenfeld, N. et al. Angiotensin Converting Enzyme Inhibitors: Derivatives lGlutarylindoline-2-carboxylic Acid. J. Med. Chem. 26, 1277-1282 (1983).

40 Lautens, M., Colucci, J. T., Hiebert, S. \& Smith, N. D. Total Synthesis of Ionomycin Using RingOpening Strategies. Org. Lett. 4, 1879-1882 (2002) 
41 Mico, A. D., Margarita, R., Parlanti, L., Vescovi, A. \& Piancatelli, G. A Versatile and Highly Selective Hypervalent Iodine (III)/2,2,6,6-Tetramethyl-1-piperidinyloxyl-Mediated Oxidation of Alcohols to Carbonyl Compounds. J. Org. Chem. 62, 6974-6977 (1997).

42 Zhang, Z. \& Tong, R. Synthetic Approaches to 2, 6-trans-Tetrahydropyrans. Synthesis 49, 4899-4916 (2017).

${ }^{43}$ Brazeau, J.-F. et al. Stereocentrolled Synthesis of C1-C17 Fragment of Narasin via a Free Radical-Based Approach. Org. Lett. 12, 36-39 (2010).

${ }^{44}$ Hiyama, T., Kimura, K. \& Nozaki, H. Chromium (II) Mediated Threo Selective Synthesis of Homoallyl Alcohols Tetrahedron Lett. 22, 1037-1040 (1981).

${ }^{45}$ Hansen, T. M. et al. Highly Chmoselective Oxidation of 1, 5-diols to $\delta$-lactones with TEMPO/BAIB. Tetrahedron Lett. 44, 57-59 (2003)

40 Zografos, A. L. \& Georgiadis, D. Synthetic strategies towards naturally occurring tetronic acids. Synthesis 3157-3188 (2006).

${ }^{41}$ Schobert, R. \& Jagusch, C. Solution-phase and solid-phase syntheses of enzyme inhibitor RK682 and antibiotic agglomerins. J. Org. Chem. 79, 6129-6132 (2005).

${ }^{42}$ Hori, K., Hikage, N., Inagaki, A., Mori, S., Nomura, K. \& Yoshii, E. Total synthesis of tetronomycin. J. Org. Chem. 57, 2888-2902 (1992).

43 Tatsuta, K., Suzuki, Y., Furuyama, A. \& Ikegami, H. The first total synthesis of a tetracyclic antibiotic, (-)-tetrodecamycin. Tetrahedron Lett. 47, 3595-3598 (2006).

${ }^{44}$ Markó, I. E., Richardson, P. R., Bailey, M., Maguire, A. R. \& Coughlan, N. Selective manganesemediated transformations using the combination: $\mathrm{KMnO}_{4} / \mathrm{Me}_{3} \mathrm{SiCl}$. Tetrahedron Lett. 38, 2339-2342 (1997).

45 Sabbah, M., Bernollin, M., Doutheau, A., Soulère, L. \& Queneau, Y. Med. Chem. Commun. 4, 363-366 (2013).

${ }^{46}$ Roush, W. R. Concerning the Diastereofacial Selectivity of the Aldol Reactions of $\alpha$-Methyl Chiral Aldehydes and Lithium and Boron Propionate Enolates. J. Org. Chem. 56, 4151-4157 (1991).

${ }^{47}$ Masamune, S., Choy, W., Petersen, J. S. \& Sita, L. R. Double Asymmetric Synthesis and a New Strategy for Stereochemical Control in Organic Synthesis. Angew. Chem. Int. Ed. 24, 1-30 (1985).

${ }^{48}$ Heathcock, C. H. \& Flippin, L. A. Acyclic Stereoselection. 16. High Diastereofacial Selectivity in Lewis Acid Mediated Additions of Enolsilanes to Chiral Aldehydes. J. Am. Chem. Soc. 105, 1667-1668 (1983). 
${ }^{49}$ Evans, D. A., Yang, M. G., Dart, M. J., Duffy, J. L. \& Kim, A. S. Double Stereodifferentiating Lewis Acid-Promoted (Mukaiyama) Aldol Bond Constructions. J. Am. Chem. Soc. 117, 95989599 (1995).

${ }^{50}$ Nicolaou, K. C., Estrada, A. A., Zak, M., Lee, S. H., Safina, B. S. A mild and selective method for the hydrolysis of esters with trimethyltin hydroxide, Angew. Chem. Int. Ed. 44, 1378-1382 (2005)

${ }^{51}$ Hoffmann, R. W., Conformation design of open-chain compounds, Angew. Chem. Int. Ed. 39, 2054-2070 (2000)

52 Evans, D., Chapman, K. \& Carreira, E. Directed reduction of $\beta$-hydroxy ketones employing tetramethylammonium triacetoxylborohydride. J. Am. Chem. Soc. 110, 3560-3578 (1988).

${ }^{53}$ Bray, M.-A. et al. Cell Painting, a high-content image-based assay for morphological profiling using multiplexed fluorescent dyes. Nat. Protoc. 11, 1757-1774 (2016).

54 Svenningsen, E. B. \& Poulsen, T. B. Establishing cell painting in a smaller chemical biology lab - A report from the frontier. Bioorg. Med. Chem. 27, 2609-2615 (2019).

${ }^{55}$ Nannenga, B. L. \& Gonen, T. The cryo-EM method microcrystal electron diffraction (MicroED). Nat. Meth. 16, 369-379 (2019). 